\title{
Leipzig Sommer 1823
}

\section{KARL ZIEGLER}

[...] in Leipzig hielt er [Grabbe] sich mehre Wochen auf und nachdem hier wiederum sein Glücksstern geschienen, und sich ihm eine ziemlich günstige bürgerliche Stellung dargeboten, die er aber launenhaft und eigensinnig von der Hand gewiesen, reiste [S. 57] er über Braunschweig zurück nach Detmold. Ich sage, er wies in Leipzig eine glückliche Stellung von der Hand. Der Rath [Heinrich] Blümner hatte ihn nämlich schon von der Zeit her, wo Grabbe in Leipzig studirte, liebgewonnen, weil er an seinen mannigfachen Kenntnissen, seinem schlagenden Witz und seinen phantasievollen Einfällen Vergnügen fand und bot ihm an, falls er sich examiniren ließe, wolle er eine Anstellung in Leipzig für ihn befördern. Grabbe wollte indessen auf dies Anerbieten nicht eingehen und brach mit dem Rath Blümner, der sehr dringend gewesen zu sein scheint, auf eine sehr sonderbare Weise. Nachdem jener ihm das Anerbieten gestellt und eine ausweichende Antwort erhalten, saß einmal Grabbe in Gohlis hinter Eierkuchen und Bier, als auch Hr. Blümner hereintrat, sich zu ihm setzte und ein verbindliches Gespräch mit ihm einzuleiten suchte. Da nun schnob Grabbe von der Seite: O Gott, o Gott! lassen Sie mich zufrieden - der schöne Eierkuchen wird mir ganz kalt durch Ihr ewiges Sprechen - ich habe jetzt keine Zeit zu hören. - Grabbe suchte später das Benehmen dadurch zu entschuldigen, daß die Tochter des Raths Blümner eine zarte Neigung zu ihm gefaßt und ihren Vater zu dem Anerbieten vermocht habe, um ihn zu fesseln, und das sei ihm zuwider gewesen. Vielleicht war dies übrigens nichts als eine Einbildung Grabbe's, [S. 58] der nur zu oft geneigt war, hinter dem Edelmuth Anderer eigennützige Triebfedern hervorzusuchen. - 